\title{
Integrating the ISO/IEC 15288 Systems Engineering Standard with the PMBoK Project Management Guide to Optimize the Management of Engineering Projects
}

\author{
Rui XUE, Claude Baron, Philippe Esteban and Li Zheng
}

\begin{abstract}
As economic pressure continues to mount worldwide, cooperation between people, companies and even countries is becoming increasingly needed. At the same time, the scale of project is being revised upwards daily. In order to ensure the success of large scale projects, the manner in which cooperation is set up between different teams, such as systems engineers and project managers, is becoming an important issue. Cooperation between systems engineering and project management is now key in this respect. On the other hand, it is widely recognized that the use of standards can improve the success ratio. Thus, integration using standards or guides from systems engineering and project management can help companies improve their competitiveness. A host of standards or guides have already been published in both domains. The purpose of this paper is to choose those most frequently used standards or guides from the systems engineering and project management in order to compare and build a bridge between them and provide a view shared by systems engineers and project managers enabling them to carry out the project effectively.
\end{abstract}

R. XUE $(\bowtie) \cdot$ C. Baron · P. Esteban · L. Zheng

LAAS, CNRS, 7 av. du col. Roche, F-31400 Toulouse, France

e-mail: rui.xue@laas.fr

C. Baron

e-mail: claude.baron@laas.fr

P. Esteban

e-mail: philippe.esteban@laas.fr

L. Zheng

e-mail: li.zheng@laas.fr

R. XUE · C. Baron $\cdot$ L. Zheng

INSA, LAAS, Université de Toulouse, F-31400 Toulouse, France

P. Esteban

UPS LAAS, Université de Toulouse, F-31400 Toulouse, France

(C) Springer International Publishing Switzerland 2016

G. Auvray et al. (eds.), Complex Systems Design \& Management,

DOI 10.1007/978-3-319-26109-6_25 